\title{
An Observational Review and Analysis of Qualitative Data to Explore the Benefits of Equine Assisted Learning in Improving the Engagement of Adolescents with Complex Learning Needs, within the Educational Setting
}

Gabrielle Madders, Ruth Orrell-Stokes*

Derby College in Affiliation with The University of Derby

${ }^{*}$ Corresponding Author email: ruth.orrellstokes@derby-college.ac.uk

Article Histary

Received: 29 May 2019

Revised: 10 July 2019

Accepted: 11 July 2019

Published: 22 July 2019

Student(s)

- Gabrielle Madders

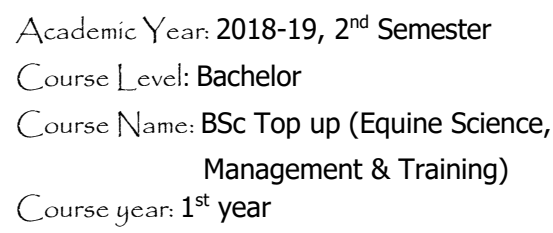

- $\quad$ Ruth Orrell-Stokes

\section{ABSTRACT}

The study determined whether Equine Assisted Learning (EAL) acted as a positive influence to improve the engagement of adolescents with complex learning needs, within their educational setting. The past two years has seen a continuous increase in the number of pupils with complex learning needs in the UK, from 1,244,255 in January 2017 to 1,276,215 in January 2018 , an increase from $14.4 \%$ to $14.6 \%$. These increasing figures provide a clear rationale for the requirement for a greater utilisation of various learning intervention tools, to begin to meet the dynamic needs of these learners. Seven participants engaged in six EAL sessions over six weeks and were involved in an array of unmounted EAL activities. Questionnaires were formulated with reference to the "Student Engagement (SE) Survey" and were presented to both staff and parents at three points throughout the study, along with Carpenters approved engagement scale for staff to complete weekly, within the lesson following the EAL session. Furthermore, observational research was conducted by the researcher to generate a supportive discussion for the obtained results. Through the quantitative data formulated no significant difference was shown, however a moderate positive correlation between the before and after results of staff and parent questionnaires was presented (Staff Questionnaire $\mathrm{p}=.119366$. Parent Questionnaire $\mathrm{p}=.145547)$. Further trends also began to emerge, with correlations forming between improved engagement and specific EAL activities, providing a direction for future research.

Keywords: Equine Assisted Learning, Equine, Engagement, Learning, Education

\section{Introduction}

Pupils with complex learning needs have been described as a "21st century frontier" [1] [2]and have been documented to present substantial challenges to educators. Due to the complexity of these pupils learning needs, they require unique and interchanging learning interventions and pathways, which offer them the specific support necessary to engage effectively in the learning process [3] [4]. A huge question which arises 
from this, is whether the current educational system allows for this effective engagement and offers the personalised learning required to meet these pupils layered needs. Therefore, the research attempted to explore and determine whether EAL played a role in achieving effective engagement within the educational setting.

Researchers have claimed that engaged behaviour is the most successful predictor of efficient learning [5] [6] and that without engagement, there is no effective teaching, deep learning or quality progress [7]. It is vital that individuals with complex learning needs are actively taught to release their motivation, unlock their curiosity and increase their participation, in ways that match their individual learning styles. Through introducing various learning interventions and experiences, educators can encourage a form of personal inquiry within pupils and in doing so, unlock the journey to optimal engagement in learning [1].

As previously stated, the past two years has seen a continuous increase in the number of pupils with complex learning needs in the UK, from 1,244,255 in January 2017 to 1,276,215 in January 2018, an increase from $14.4 \%$ to $14.6 \%$ [8]. These increasing figures provide a clear rationale for the requirement for a greater utilisation of various learning intervention tools, to begin to meet the dynamic needs of these learners. Furthermore, according to current Government statistics, pupils with recognised complex learning needs were accountable for the highest proportion of exclusion rates within the UK, between 2016 and 2017. With $46.7 \%$ of permanent exclusions recorded and $44.9 \%$ of fixed period exclusions recoded [9]. The greatest reasoning documented for these exclusion rates is persistent disruptive behaviour, resulting in a lack of focus [9]. This emerging factor must be considered in relation to its effective management and reduction. It can be argued that through introducing pupils to various learning strategies such as EAL, educators will be able to engage pupils and personalise their learning more effectively to begin to diminish this distributive behaviour, as they begin to focus on specific tasks [10].

Currently there is no scientific research investigating the effects EAL may have as a learning intervention tool, to increase the engagement of pupils with complex learning needs, within their educational setting. However, there is a substantial amount of scientific literature regarding the use of EAL as a strategy to improve the general school functioning, self-esteem, confidence, problem solving skills and teamwork of these individuals [11] [12] [13] [14] [15]. A major vice however associated with much of this research, is that data obtained is vulnerable to substantial bias and has been left open to many methodological flaws, with small sample sizes, a lack of standardised EAL methods to act as a comparison to alternative intervention strategies and a lack of post treatment follow up reviews [16]. Furthermore, much of the research is based upon an analysis of qualitative data, with little evidence based upon quantitative results, meaning studies may lack empirical soundness. However, the current conclusions obtained from these studies are encouraging, so may act as a director for future empirical investigation in this field [17].

Many school psychologists have recognised the capability of animals to enhance the dynamics within a classroom through improved positivity and engagement. With issues such as self-efficacy, speech disorders and impulse behaviour disorders being targeted through horseback riding and unmounted activities [18]. The fact that these forms of learning intervention are utilised by educators today, along with the current promising research regarding the use of EAL for individuals with complex learning needs, shows real encouragement for its future use within educational establishments, with the backing of further targeted scientific investigation.

\section{Methodology}

The sessions were undertaken at a land-based FE college within the United Kingdom which caters for students aged 14 and over. With the inclusion of a 14-16 study programme provision, a 16-19 study programme, apprenticeships and adult learning programmes. At present the college obtains 1454 learners, with over 4500 learners across all campuses within the constituency. The percentage of learners from a minority ethnic background is low and in line with that of the local population. In regard to the current OFSTED report, the overall effectiveness, as determined at the latest inspection in May 2018, was rated as requires improvement across all areas reviewed [19]. 
Madders et al., Adv. J. Grad. Res.; Vol. 6, Issue 1, pp: 53-59, July 2019

The demographic of this study sample will be both male and females, aged between 18-22, with a sample size of six participants. The study sample includes participants with an array of complex learning needs all within an educational setting. The participants individual conditions include; Spina bifida, ASD and Down syndrome. This information was attained through the learners personal Educational Health Care Programmes (EHCP).

The method of EAL was unmounted. Within the session's the participants were involved in husbandry type activities including; grooming and in loose schooling sessions, with the involvement of 'energy', 'leading' and 'obstacle' activities. The sessions were delivered by a professionally trained LEAP registered EAL practitioner, with the researcher and two support staff also being present throughout the entirety of the sessions. Sessions ran for one hour once a week for a period of six weeks, with the inclusion of one classroom based reflective session. The two horses chosen were used to being handled by novice or inexperienced learners regularly and are known to express quiet temperaments.

The engagement scale which will be presented to staff to complete, was formulated through "The Complex Learning Difficulties and Disabilities Research Project: Developing meaningful pathways to personalised learning" [3]. Staff will be asked to complete the engagement scale during the lesson, directly following the EAL sessions. Questionnaires were formulated with reference to a pre-tested questionnaire assessment. The "Student Engagement (SE) Survey" [20], was utilised and has a primary focus of cognitive level and personal skills. Questionnaires were presented to staff and parents/guardians of participants at the start, middle and end of the investigative process. Feedback from participants was withheld. Observational research was conducted by the researcher who acted as a bystander and had no direct influence over the running of the sessions, or their structural format.

\section{Results}

The results were formulated from the data that was collected through the pre-tested questionnaire assessment and an approved engagement scale, over the course of the six-week investigative research. Regarding both methods of data collection, any increases of data was recorded, to detect any significance difference in engagement, as a result of the EAL sessions.

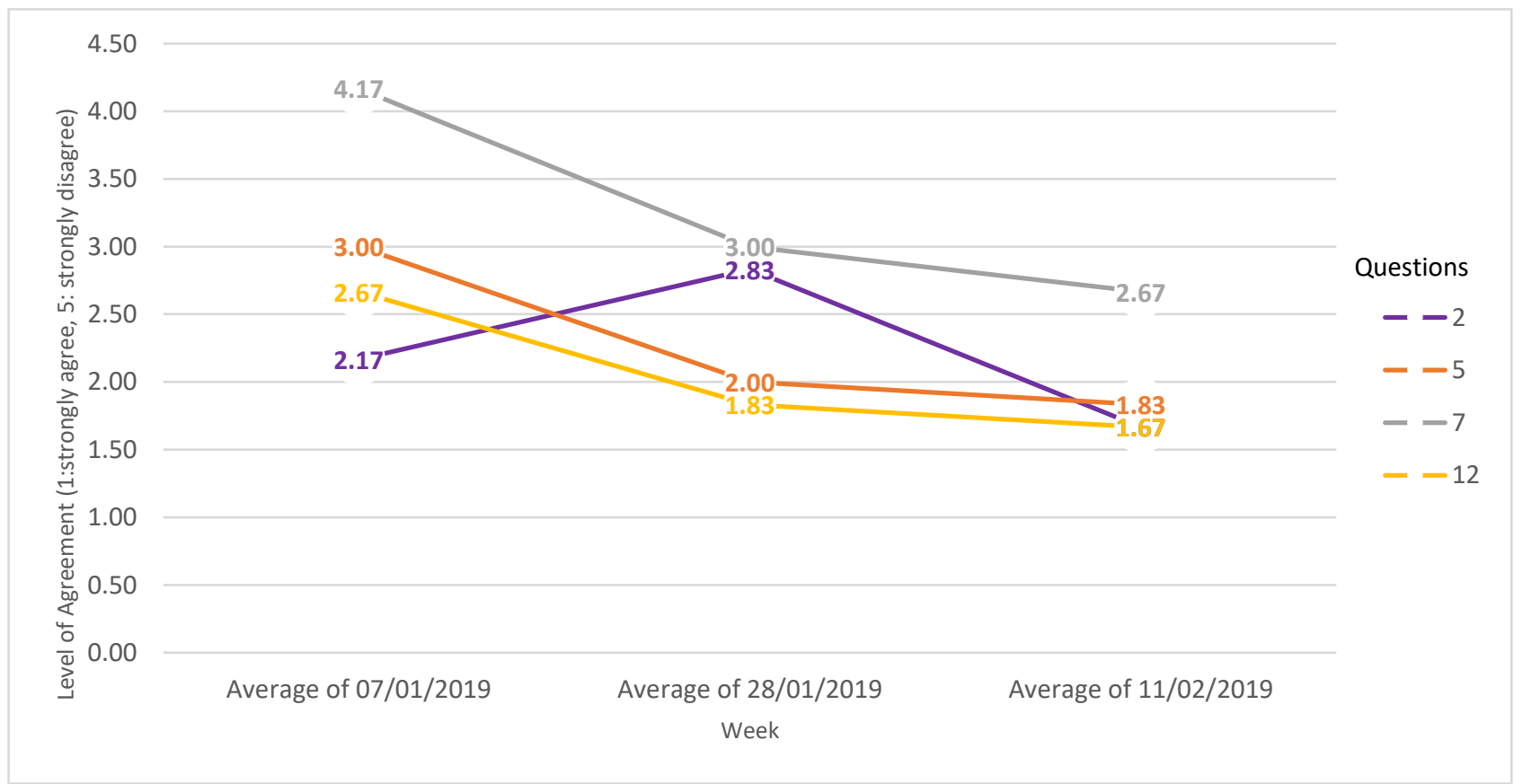

Figure 1: The average response from staff questionnaires, over each week, based on questions; $2,5,7 \& 12$.

Through the data presented in Figure 1 and the information displayed in Table 1, the following improvements can be drawn. From question 2 improvements to the participants ability to adapt can be observed, when comparing the first week of data to the last, with improvements from an average of 2.17 
(agree) to an average of 1.67 (strongly agree). However, within the second questionnaire presented a decrease to the participant's ability to adapt was observed. Question 12 also displays progressive improvements over all three questionnaire assessments, with an average of 2.67 (agree), recorded within the first questionnaire and an average of 1.67 (strongly agree) recorded within the final questionnaire. The most substantial improvements can be seen from question 7 with improvements from an average of 4.17 (disagree) in the first questionnaire, to an average of 2.67 (agree) in the final questionnaire. Question 5 also indicates prominent improvements with an average of 3.00 (natural) being produced in the first questionnaire and an average of 1.83 (strongly agree) being produced within the last questionnaire. This data corresponds with the statistical analysis results formulated against the Pearson Correlation Coefficient test, which presented a moderate positive correlation between the before and after results ( $\mathrm{p}=$.119366). The remaining questions have not been included within this analysis, due to inconsistencies from the baseline score, to the final data collected

Table 1: Questions presented to staff and parents within questionnaire assessment.

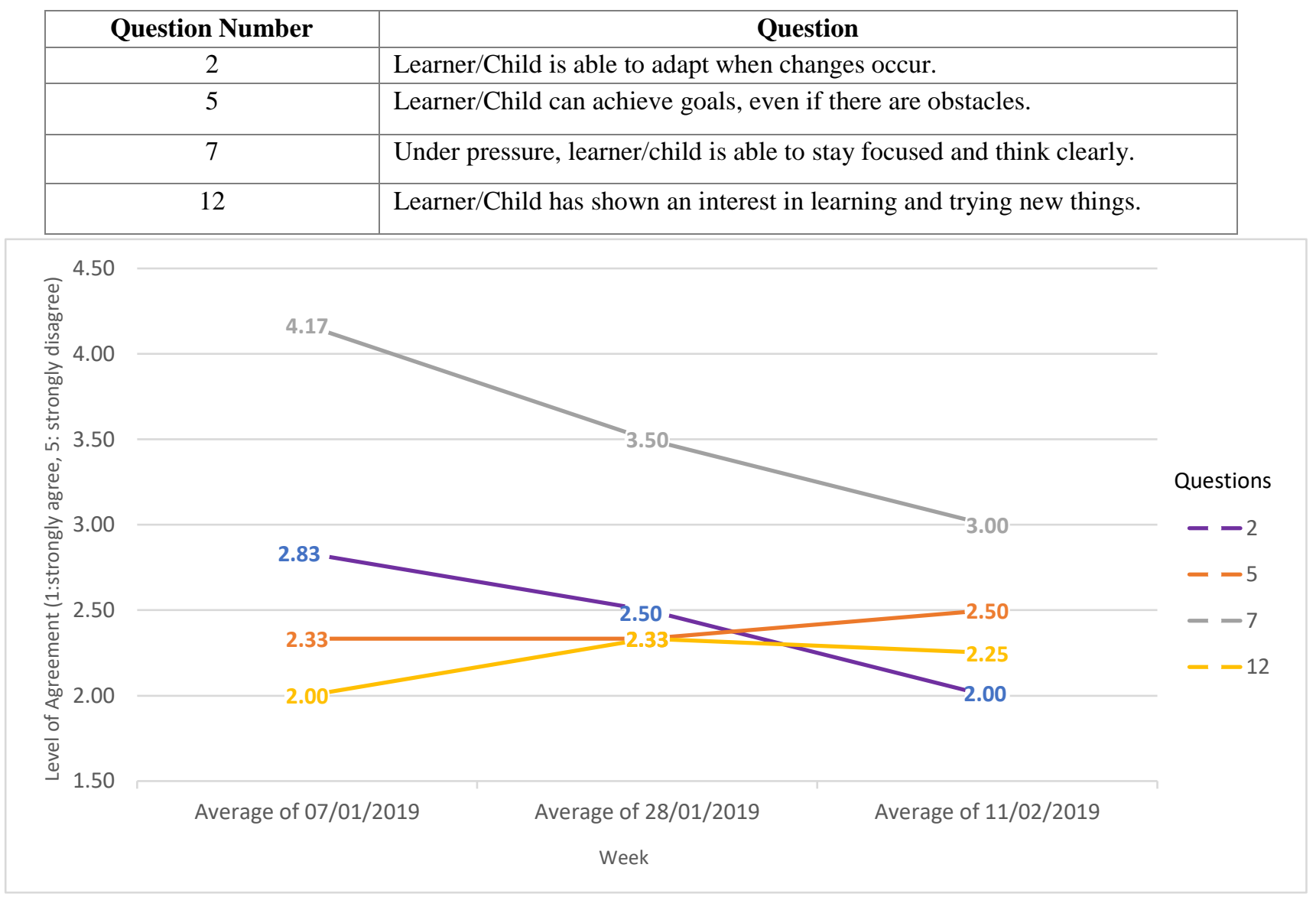

Figure 2: The average response from parent questionnaires, over each week, based on questions; $2,5,7 \& 12$.

The results presented in Figure 2, along with the information provided in Table 1, allows improvements to be drawn regarding the parent's perception of their child's ability to adapt and focus. Question 7 produces the more substantial data, with a greater improvement produced from the first questionnaire to the last, as data fluctuates from an average of 4.17 (disagree) to an average of 3.00 (neutral). Question 2 also allows developments to be drawn. Although the data remains within the same bracket of "agree", an increase to the positive data pattern emerges, with improvements from an average of 2.83 to an average of 2.00 . This data corresponds with the statistical analysis results formulated against the Pearson Correlation Coefficient test, which presented a moderate positive correlation between the before and after results $(\mathrm{p}=.145547)$. From questions 5 and 12 a decline to each participant desire to try new things and achieve goals can be observed; however, the data does remain within the same bracket of "agree", suggesting only slight 
Madders et al., Adv. J. Grad. Res.; Vol. 6, Issue 1, pp: 53-59, July 2019

alterations to this data pattern. The remaining questions have not been included within this analysis, due to inconsistencies from the baseline score, to the final data collected.

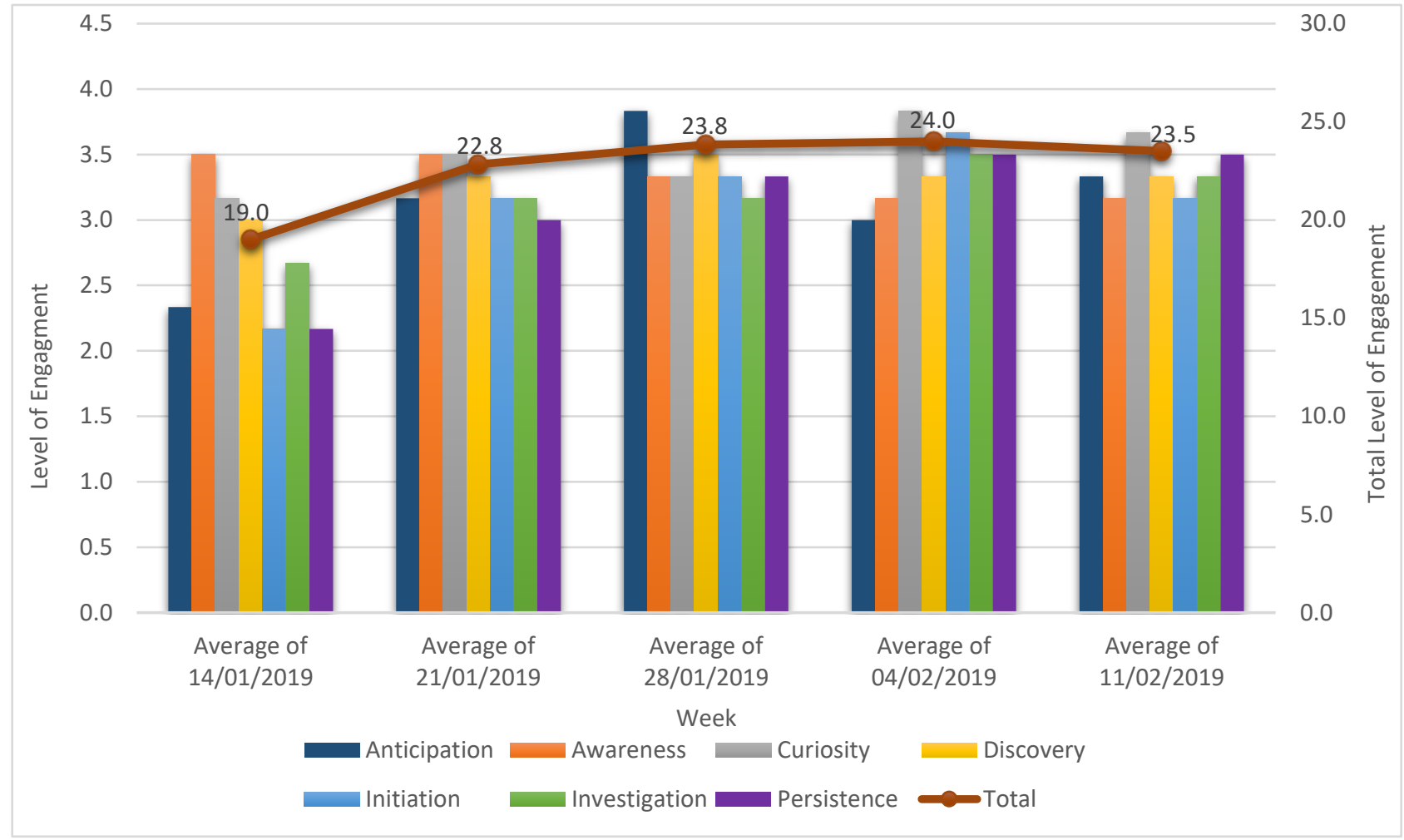

Figure 3: The average engagement of participants, against all indicators over each week and the overall total level of engagement.

From Bar Chart (Figure 3) we can begin to draw conclusions, that on average each participants level of persistence continued to increase throughout the weeks of investigation. The levels of initiation also appear to increase, although a decline is recorded on the final week. The average level of awareness appears to decrease over each week. However, each other indicator produces a steady incline, with an increase in each of these indicators apparent in the final week of investigation, compared to the first week. Regarding the total level of engagement, weeks three and four produce the most prominent data, with all participants during week three scoring either three or four on their level of discovery and anticipation and $83 \%$ of participants scoring either three or four on their level of awareness, curiosity, investigation, initiation and persistence. Furthermore, in week four all participants scored either three or four on their level of curiosity and investigation, with $83 \%$ of participants scoring either three or four on their level of awareness and discovery. It can also be observed, that on average each participant shows an increased total level of engagement from their first EAL session to their last.

\subsection{Significance}

Regarding the engagement scale, the Single $T$ test was utilised to compare the median of a single sample of scores to the known population mean. This test was appropriate for the results in question due to the small sample size and was utilised to demonstrate whether a change occurred over the various time points. The significance of each indicator over each week was tested, along with the individual participants significance over each week, covering all engagement indicators. In relation to both tests, no significance was shown. Pearson Correlation Coefficient test was employed to measure the strength in the linear association, between the questionnaires presented to staff and parents, prior to the EAL sessions commencing and as the sessions came to a close. No significance was found, however as displayed in Line Graphs (Figure 1 \& 
2), a moderate positive correlation could be observed between the before and after results from both staff and parents.

\section{Conclusion}

Through the findings it can be concluded that no significant level of improvement can be drawn. However, positive trends did begin to emerge through the results, which would appropriately inform future research to begin to further validate EAL as an effective learning intervention strategy. The evidence from this study suggests that specific techniques have a greater influence in their effect, on improving the engagement of learners with complex learning needs. This finding can be seen as key to the development of previous research surrounding the impacts of EAL to tackle engagement, as a recurrent flaw had been a lack of emphasis on the specific strategies and techniques utilised within EAL sessions, to understand why and how the reported positive effects occur. Through this study, a greater understanding can be drawn, which extends researchers practical knowledge on the topic and will confidently inform future investigations, to begin to resolve this research issue.

\section{Declarations}

\subsection{Acknowledgments}

Acknowledgement to the anonymous education center and participants that were involved in the research.

\subsection{Study Limitations}

Issues can be raised surrounding the small sample size of this study, due to difficulties generalising results to the wider populace and possible increases to the margin of error. However, due to the severe complexities of participants conditions and a limit on staff availability, this was attainable for the investigative research in question.

\subsection{Ethical Approval}

Ethical approval was obtained from the University of Debry with reference number 93395612.

\subsection{Informed Consent}

Written consent was received from all those that participated in the research.

\subsection{Funding Source}

None

\subsection{Competing Interests}

The authors declared that no conflict of interest in publication of this article.

\section{How to Cite this Article:}

G. Madders and R. Orrell-Stokes, “An Observational Review and Analysis of Qualitative Data to Explore the Benefits of Equine Assisted Learning in Improving the Engagement of Adolescents with Complex Learning Needs, within the Educational Setting", Adv. J. Grad. Res., vol. 6, no. 1, pp. 53-59, Jul. 2019. doi: 10.21467/ajgr.6.1.53-59

\section{References}

[1] B, Carpenter; B, Cockbill; D, Wiggett \& J, Egerton. Engaging children with complex learning difficulties and disabilities in the Primary Classroom. Primary Australian article. 2013. https://engagement4learning.com/wp-content/uploads/2016/11/PrimaryAustralian-article-Carpenter-et-al-2013.pdf

[2] L, Murphy; J, Wilson \& S, Greenberg. Equine-Assisted Experiential Learning in Occupational Therapy Education. Journal of Experiential Education, vol 40, no. 4, pp. 366 -376. 2017.

[3] B, Carpenter; J, Egerton; T, Brooks; B, Cockbill; J, Fotheringham \& H, Rawson. The Complex Learning Difficulties and Disabilities Research Project: Developing meaningful pathways to personalised learning (final report). London: Specialist Schools and Academies Trust (now The Schools Network). 2011. http://complexld.ssatrust.org.uk 
Madders et al., Adv. J. Grad. Res.; Vol. 6, Issue 1, pp: 53-59, July 2019

[4] K, Liou; D, Jamorabo; R, Geha; C, Crawford; P, George \& F, Schiffman. "Foreign Bodies: Is It Feasible to Develop Tolerance for Ambiguity among Medical Students through Equine-Facilitated Learning?" Medical Teacher, pp. 1-3. 2019.

[5] R, Iovannone; G, Dunlap; H, Huber \& D, Kincaid. 'Effective educational practices for students with autism spectrum disorders', Focus on Autism and Other Developmental Disabilities, vol 18, no.3, pp. 150-165. 2003.

[6] D, Taylor; B, Picker; D, Woolever; EK,Thayer; PA, Carney \& AB, Galper. A pilot study to address tolerance of uncertainty among family medicine residents. Family Medicine, vol 50, pp.531-538. 2018.

[7] B, Carpenter. A Vision for the 21st Century Special School. London: Specialist Schools and Academies Trust, pp. 34-37. 2010. https://webcontent.ssatuk.co.uk/wp-content/uploads/2016/10/05105527/CLDD-Booklet-1-vision-for-21st-century-specialschool.pdf

[8] Special Education Needs in England. Department for Education. [online] Available at: https://assets.publishing.service.gov.uk/government/uploads/system/uploads/attachment_data/file/729208/SEN_2018_Text.pdf Accessed: 01/01/2019. 2018.

[9] Department for Education. Permanent and Fixed Period Exclusions in England: 2016 to 2017. Government National Statistics. Last updated $\quad 6 \quad$ August $2018 . \quad$ Available https://assets.publishing.service.gov.uk/government/uploads/system/uploads/attachment_data/file/726741/text_exc1617.pdf. Accessed: 09/02/19. 2018.

[10] Wiley, C. Theraputic and Health Benefits of Horse-Human Interactions. Honours Senior Thesis/Projects Western Oregon University, pp. 143. 2017. https://digitalcommons.wou.edu/honors_theses/143

[11] M.E, O'Haire; S.J, McKenzie; S, McCune \& V, Slaughter. Effects of classroom animal-assisted activities on social functioning in children with Autism Spectrum Disorder. Journal of Alternative and Complementary Medicine, vol 20, no. 3, pp. 162-168. 2014.

[12] P, Pendry; A M, Carr; A N, Smith \& S, Roeter. Improving Adolescent Social Competence and Behavior: A Randomized Trial of an 11-Week Equine Facilitated Learning Prevention Program. Journal of Primary Prevention, vol 35, no. 4, pp. 281-293. 2014.

[13] C, Llambias; J, Magill-Evans; V, Smith \& S, Warren. Equine-assisted occupational therapy: Increasing engagement for children with autism spectrum disorder. American Journal of Occupational Therapy, vol 70, no. 6. 2016.

[14] L, Murphy; J, Wilson \& S, Greenberg. Equine-Assisted Experiential Learning in Occupational Therapy Education. Journal of Experiential Education, vol 40, no. 4, pp. 366 -376. 2017.

[15] B, Saggers \& J, Strachan. "Horsing Around: Using Equine Facilitated Learning to Support the Development of Social-emotional Competence of Students at Risk of School Failure." Child \& Youth Services, pp. 231-52. 2016.

[16] J. A, Lentini \&, Knox. A qualitative and quantitative review of equine facilitated psychotherapy (EFP) with children and adolescents. The Open Complementary Medicine Journal, vol 1, no. 1, pp. 51-57. 2009.

[17] J.E, Cartinella. Social Skills Improvement for an Adolescent Engaged in Equine Assisted Therapy: A Single Subject Study. PHD Thesis, Pacific University, Pacific. 2009.https://core.ac.uk/download/pdf/48844142.pdf

[18] F, Roberts; J, Bradberry \& C, Williams. Equine-facilitated psychotherapy benefits students and children. Holistic Nursing Practice, vol 18, no. 1, pp. 32-35. 2004.

[19] OFSTED. Further education and skills inspection report. Contains public sector information licensed under the Open Government Licence v3.0. Crown copyright. Available at: https://files.api.ofsted.gov.uk/v1/file/2779301. Accessed: 09/02/19. 2018.

[20] S, Ahlfeldt; S, Mehta \& T, Sellnow. Measurement and analysis of student engagement in university classes where varying levels of PBL methods of instruction are in use. Higher Education Research \& Development, vol 24, no. 1, pp. 5-20. 2005.

Publish your research article in AIJR journals-

$\checkmark$ Online Submission and Tracking

$\checkmark$ Peer-Reviewed

$\checkmark$ Rapid decision

$\checkmark \quad$ Immediate Publication after acceptance

$\checkmark$ Articles freely available online

$\checkmark$ Retain full copyright of your article.

Submit your article at journals.aijr.in
Publish your books with AIJR publisher-

$\checkmark \quad$ Publish with ISBN and DOI.

$\checkmark \quad$ Publish Thesis/Dissertation as Monograph.

$\checkmark$ Publish Book Monograph.

$\checkmark \quad$ Publish Edited Volume/ Book.

$\checkmark$ Publish Conference Proceedings

$\checkmark \quad$ Retain full copyright of your books.

Submit your manuscript at books.aijr.org 